\title{
Strength and grain refinement of Ti-30Zr-5Al-3V alloy by Fe addition
}

\author{
Jun $\mathrm{Li}^{\mathrm{a}}$, Xinyu Zhang ${ }^{\mathrm{a}^{*}}$, Jiaqian Qin ${ }^{\mathrm{b}, \mathrm{a}^{*}}$, Mingzhen $\mathrm{Ma}^{\mathrm{a}}$, Riping Liu ${ }^{\mathrm{a}}$ \\ ${ }^{a}$ State Key Laboratory of Metastable Materials Science and Technology, Yanshan \\ University, Qinhuangdao, P.R. China \\ ${ }^{\mathrm{b}}$ Metallurgy and Materials Science Research Institute, Chulalongkorn University, \\ Bangkok, Thailand \\ xyzhang@ysu.edu.cn \\ jiaqian.q@chula.ac.th \\ ${ }^{*}$ Corresponding author.
}

\begin{abstract}
The influence of various Fe contents on the microstructure and mechanical properties of Ti-30Zr-5Al-3V (ZTAV) alloy was investigated. After Fe addition, the grain refinement is obvious and the phase composition changes as $\alpha^{\prime}+\beta \rightarrow \beta$. Ti-30Zr-5Al-3V-0.5Fe exhibits a better mechanical property $\left(\sigma_{\mathrm{b}} \approx 1420 \mathrm{MPa}, \varepsilon_{\mathrm{f}} \approx 5.34 \%\right)$ than Ti-30Zr-5Al-3V $\left(\sigma_{\mathrm{b}} \approx 1302 \mathrm{MPa}, \varepsilon_{\mathrm{f}} \approx 4.28 \%\right)$. Highest ultimate tensile strength $\left(\sigma_{\mathrm{b}} \approx 1667 \mathrm{MPa}, \quad \varepsilon_{\mathrm{f}} \approx 2.34 \%\right)$ have been achieved in Ti-30Zr-5Al-3V-1.5Fe. The mechanical properties change owe to the phase transformation, grain refinement, and solid solution strengthening caused by Fe addition.
\end{abstract}

Keywords: TiZrAlV alloys; Fe addition; Grain refinement; Mechanical properties 


\section{Introduction}

Titanium alloys are very attractive materials for aerospace and automotive industries due to their high strength-to-density ratio, good hardenability, excellent fatigue performance, and environmental resistance[1, 2]. Recently, many investigations have been performed on the development of high strength $\mathrm{Zr}$-Ti based alloys. Ti and $\mathrm{Zr}$ are belonging to the same main group (IVB), their physical and chemical properties are similar. They both have two kinds of crystal structure ( $\alpha$ - and $\beta$-phase). $\alpha$-phase (hcp) can be stable when the temperature is lower than $\alpha / \beta$ transus temperature, otherwise, $\beta$-phase (bcc) is stable phase. Due to their similar chemical and physical properties, Ti and $\mathrm{Zr}$ are infinitely miscible solid solution. Solution strengthening effect is significant in Zr-Ti based alloys, such as Zr-Ti-Al[3, 4] and Zr-Ti-Al-V (ZTAV) [6, 7] etc. $\mathrm{Zr}$-Ti based alloys have shown great potential to be structural materials in aerospace and other fields.

It has been found that ZTAV alloys exhibit good mechanical property, such as Ti-30Zr-5Al-3V, it shows high strength $\left(\sigma_{\mathrm{b}} \approx 1258 \mathrm{MPa}, \varepsilon_{\mathrm{f}} \approx 8.4 \%\right.$, forged state $)$ [8]. This result is owing to the addition of $\mathrm{Al}$ and $\mathrm{V}$. Though their content is limited, the influence on mechanical property is very obvious. It indicates that the addition of alloying element is an effective way to change the mechanical properties, phase component and phase transformation temperature $[9,10]$. The previous study demonstrated that the $\mathrm{Fe}$ is an effective grain refinement element for $\mathrm{Al}$ and $\mathrm{Mg}$ alloy [11]. However, grain refinement and strength enhancement of ZrTi alloy with addition 
of Fe has not yet been reported. In this work, the grain refinement and strength enhancement of Ti-30Zr-5Al-3V (ZTAV) with Fe addition as the solid solution element was systematically studied. The results reveal that the grain size changes with the Fe content, which is one of the main factors to enhance the mechanical properties of the TiZr-based alloys. Also, the strength of alloys as a function of the concentration of the solute atom Fe was achieved with the solid solution strengthening scheme.

\section{Experimental}

All ingots of Ti-30Zr-5Al-3V- $x \mathrm{Fe}(x=0,0.5,1.0,1.5,2.0,2.5)(\mathrm{wt} \%)$ (denoted as TZAFV) were prepared by arc-melting technique in a Ti-gettered argon atmosphere. The raw material is prepared by a mixture of sponge $\mathrm{Zr}(\mathrm{Zr}+\mathrm{Hf} \geq 99.5 \mathrm{wt} \%)$, sponge $\mathrm{Ti}(99.7$ $\mathrm{wt} \%)$ and industrially pure $\mathrm{Al}(99.5 \mathrm{wt} \%), \mathrm{Fe}(99.9 \mathrm{wt} \%), \mathrm{V}(99.9 \mathrm{wt} \%)$. To ensure compositional uniformity, each ingot was re-melted at least ten times. The actual compositions of each ingot are shown in Table 1 . The ingots were heated to $1000^{\circ} \mathrm{C}$, held for $0.5 \mathrm{~h}$, and then hot rolled into plated samples with a thickness of $5.2 \mathrm{~mm}$. The plated samples were cooled in the air after rolling. The total deformation was $70 \%$. Hot rolled samples were removed about $1.5 \mathrm{~mm}$ on each rolled surfaces for following tests and analysis.

To analyze the phase structure of hot rolled plated samples, the centers of plated samples were tested by X-ray diffraction (XRD) using copper $K \alpha$ X-radiation (ASTM: D5380-93(2014)) at a diffraction angle (20) range of $20^{\circ}-100^{\circ}$ and at an accelerating voltage of $40 \mathrm{kV}$ and a current of $40 \mathrm{~mA}$. The specimens for XRD were mechanically polished by $\mathrm{SiC}$ waterproof emery papers up to 2500 grit. Differential scanning 
calorimetry (DSC) was used to test the phase transition temperatures in heating velocity $10^{\circ} \mathrm{C} / \mathrm{min}$ adopting the standard of ASTM: F2004-05(2010). Microstructure of the plated samples was observed through Olympus DSX500 type optical microscopy (OM). For TEM, the specimens were mechanically polished with SiC waterproof emery papers up to 2500 grit to a thickness of approximately $30 \mu \mathrm{m}$. After that, they were twin-jet electrochemically polished in a solution containing perchloric acid (10 vol $\%$ ) and methanol (90 vol $\%$ ) at $15 \mathrm{~V}$ and below $-30^{\circ} \mathrm{C}$. For OM, the specimens were mechanically polished using $\mathrm{SiC}$ waterproof emery paper of up to 4000 grit and to a final level of approximately $0.04 \mu \mathrm{m}$ with colloidal silica suspension. Each mirror-polished specimen was etched using aqueous solutions of hydrofluoric acid (5 vol $\%)$ and nitric acid (15 vol\%) .

Table 1 Actual alloy compositions of the examined ZrTiAlVFe alloys, wt $\%$.

\begin{tabular}{cccccc}
\hline Sample ID & $\mathrm{Ti}$ & $\mathrm{Zr}$ & $\mathrm{Al}$ & $\mathrm{V}$ & $\mathrm{Fe}$ \\
\hline ZTAV & 62.00 & 30.00 & 5.00 & 3.00 & 0 \\
ZTAFV-0.5 & 61.48 & 30.01 & 5.00 & 3.01 & 0.50 \\
ZTAFV-1 & 61.00 & 30.00 & 5.00 & 3.00 & 1.00 \\
ZTAFV-1.5 & 60.49 & 30.00 & 5.00 & 3.00 & 1.50 \\
ZTAFV-2 & 60.00 & 30.00 & 5.00 & 3.00 & 2.00 \\
ZTAFV-2.5 & 59.50 & 30.00 & 5.00 & 3.00 & 2.50 \\
\hline
\end{tabular}

Tensile samples were machined from hot-rolled plates after removing $1 \mathrm{~mm}$ thick portions from both sides of the rolled surface. The size of tensile samples is shown in 
Figure 1. Uniaxial tensile tests (ASTM: E8/E8M-11) were performed on an INSTRON 5982 machine at a strain rate of $5 \times 10^{-4} \mathrm{~s}^{-1}$. The strain during the entire testing process was monitored using an extensometer with a 12.5 gauge length. The tensile direction was parallel to the rolling direction of the sample. The microhardness of the polished alloys is measured with a load of $200 \mathrm{gf}$ for $10 \mathrm{~s}$.

\section{Results and discussion}

Figure 1 shows the XRD patterns of ZTAV and ZTAFV alloys. The XRD results show that the phase constitution and lattice parameters are changing with Fe content. Without Fe addition, all peaks match well with those of $\alpha^{\prime}$ - and $\beta$ - phases. With the Fe content increases from $0 \mathrm{wt} \%$ to $1.5 \mathrm{wt} \%$, the XRD patterns show similar curve. It indicates that they are all compose of $\alpha^{\prime}$ and $\beta$ phases[12]. The intensity of the peak of $\beta$-phase increases with the Fe content, which indicates that the content of $\beta$ phase increases with the Fe content. Meanwhile, as the atomic radius of $\mathrm{Fe}(0.126 \mathrm{~nm})$ is smaller than those of $\mathrm{Ti}(0.147 \mathrm{~nm})$ and $\mathrm{Zr}(0.160 \mathrm{~nm})$, the addition of Fe results in the lattice distortion that causes the lattice parameters of $\alpha^{\prime}-$ and $\beta$ - phase to decrease. It is shown in the XRD patterns that the peaks of $\alpha$ - and $\beta$ - phases shift toward to high angle orientation with the addition of Fe. When the Fe content increase further from $1.5 \mathrm{wt} \%$ to $2.5 \mathrm{wt} \%$, the XRD patterns show only $\beta$ phase. This is due to the reason that the eutectoid transformation of $\beta \rightarrow \alpha^{\prime}$ phase is wholly hindered when the sample cooled from hot rolling state with the increase of Fe content.

Figure 2 shows the DSC curves of TZAFV alloys. The DSC results indicate that the martensite transformation temperature of the alloys is changing with Fe content. 
The end temperature of martensite transformation of TZAFV reduces with the increasing of Fe content. This results can be attributed to the $\beta$-stabilizer element of $\mathrm{Fe}$ in $\mathrm{Ti}$ and $\mathrm{Zr}$ alloy from previous researches [13] and Ti-Fe, $\mathrm{Zr}-\mathrm{Fe}$ binary phase diagrams.

Figure 3 shows the size of optical micrographs of ZTAV and ZTAFV alloys with different Fe contents. The size of $\beta$ grain changes with Fe content increasing. When Fe content reaches $0.5 \mathrm{wt} \%$, the smallest size of $\beta$ grain can be obtained. However, the size of $\beta$ grain would increase with increasing $\mathrm{Fe}$ content. The growth restriction factor (GRF) was proposed to measure the effect of solute concentration, such as Fe and other solute elements, on grain size and crystal morphology. The grain size reaches a minimum at a critical GRF [14]. This explains why the size of $\beta$ grain reaches the smallest value when Fe content is $0.5 \mathrm{wt} \%$. Beyond the critical GRF, the transition from cellular to dendrite growth would occur, and the grain size would increase with increasing Fe content. The constitutional supercooling in ZTAFV alloys would increase with Fe content increasing. With the increase of Fe content in ZTAFV alloys, the foreign clusters, which consist of Fe atoms, would tend to grow as the flake eutectoid phase. This means that they could not serve as the potential nucleation of primary $\beta$ grains. In other words, the number of potential nucleation of primary $\beta$ grains plays a key role in the grain refinement of ZTAFV alloys with low content of Fe. Furthermore, the pinning effect of intermetallic compound on grain boundaries can be another factor which also plays an important role in the grain refinement of ZTAFV alloys with low content of Fe. The pinning effect of intermetallic compound 
can hinder the growth of primary $\beta$ grains. In the whole process of the crystallization of ZTAFV alloys, the way of grain grows, the number of potential nucleation of primary $\beta$ grains and the pinning effect on grain boundary, could contribute to the peak-valley relationship between Fe content and grain size.

Figure 4 shows the TEM images and the corresponding SAED patterns of ZTAV and ZTAFV alloys with Fe content of 0.5 wt.\% (ZTAFV-0.5), 1.0 wt.\% (ZTAFV-1), 1.5 wt.\% (ZTAFV-1.5), respectively. The SAED patterns proves that the structure of the lath or acicular grain is hep, namely $\alpha^{\prime}$ phase. It shows different morphology of $\alpha^{\prime}$ phase existed in the alloys. The $\alpha^{\prime}$ phase exists as lath in the ZTAV alloy, while it exists as acicular martensite with different width for Fe content of $0.5,1.0$, and 1.5 in ZTAFV alloy. It reveals that the morphology of $\alpha^{\prime}$ phase is dependent on the Fe content. The reported results demonstrated that the phase constitution of $\mathrm{Ti}$ and/or $\mathrm{Zr}$ based alloys will change as $\alpha \rightarrow \alpha^{\prime}$ when the alloy is cooled rapidly from a two-phase or $\beta$ phase temperature region [15]. Meanwhile, it is noticeable that the size of the grain decreases with the increasing Fe content. In ZTAV alloy, the width of $\alpha$ lath is about $0.2 \mu \mathrm{m}$. With the increase of Fe content to $0.5 \mathrm{wt} . \%$, the width of the acicular $\alpha^{\prime}$ grain decreases to $0.15 \mu \mathrm{m}$. The width of the acicular $\alpha^{\prime}$ grain further decreases to 0.1 $\mu \mathrm{m}$ when Fe content increases to 1.0 wt. $\%$. When Fe content reaches 1.5 wt. $\%$, the width of the acicular $\alpha^{\prime}$ grain decreases to $0.06 \mu \mathrm{m}$. The size of $\alpha^{\prime}$ grains is controlled by the velocity of $\alpha^{\prime}$ grain growth. The $\alpha^{\prime}$ grains form in the process of eutectoid transformation of $\beta$ phase. The velocity of eutectoid transformation in ZTAFV alloys is related to Fe content, which decreases with the increasing Fe content. Thus the 
eutectoid transformation is wholly hindered, when Fe content reaches $2.0 \mathrm{wt} \%$ in ZTAFV alloys, resulting in only $\beta$ phase existing in ZTAFV-2.0 and ZTAFV-2.5.

Table 2 Tensile properties of the studied alloys under rolling state.

\begin{tabular}{ccccc}
\hline Sample & E $(\mathrm{GPa})$ & $\sigma_{0.2}(\mathrm{MPa})$ & $\sigma_{\mathrm{b}}(\mathrm{MPa})$ & $\varepsilon_{\mathrm{f}}(\%)$ \\
\hline ZTAV & 97 & 1181 & 1302 & 4.28 \\
ZTAFV-0.5 & 92 & 1299 & 1420 & 5.34 \\
ZTAFV-1 & 100 & 1421 & 1533 & 2.49 \\
ZTAFV-1.5 & 96 & 1553 & 1667 & 2.34 \\
ZTAFV-2 & 103 & 1399 & 1538 & 1.90 \\
ZTAFV-2.5 & 79 & 1068 & 1115 & 2.00 \\
\hline
\end{tabular}

The tensile results of ZTAV and ZTAFV alloys under rolling state are presented in Figure 5. The tensile results show that the mechanical properties are obviously dependent on $\mathrm{Fe}$ content. The relationships between tensile strength, elongation and Fe content are shown in Figure 6(a) and 6(b). For ZTAV alloy, it has relatively low yield strength $\left(\sigma_{0.2} \approx 1181 \mathrm{MPa}\right)$ and ultimate tensile strength $\left(\sigma_{\mathrm{b}} \approx 1302 \mathrm{MPa}\right)$ (Table 2$)$. The ductility of ZTAV alloy is quite good, which has a relatively high total elongation of $\varepsilon_{\mathrm{f}} \approx 4.28 \%$. When the Fe content is $0.5 \mathrm{wt} \%$, the strength and ductility of the alloy are both improved. The yield strength and ultimate tensile strength of ZTAFV-0.5 both increase by $118 \mathrm{MPa}$ compared with ZTAV. ZTAFV-0.5 has a total elongation of $\varepsilon_{\mathrm{f}} \approx 5.34 \%$, which is also higher than that of ZTAV. Figure 6(c) shows the relationship 
between microhardness and Fe content, it shows similar trend as the relationship of strength and Fe content. ZTAFV-1.5 has the highest microhardness (482 $\mathrm{MPa})$, which increases by $21 \%$ as the Fe content increases from 0 to $1.5 \mathrm{wt} \%$. The TEM images indicate that Fe addition could greatly reduce the width of $\alpha^{\prime}$ lath. The narrower the $\alpha^{\prime}$ lath is, the more influence the pinning effect have on the tensile strength. The improvement of tensile strength can be explained by pinning effect and grain refinement. According to the Hall-Petch formula, the strength of the alloys increases with grain size decreasing. The improvement of ductility could be due to the decrease of $\beta$ grain size which can be observed in Figure 4(a) and 4(b). Grain refinement plays a key role in the improvement of ductility. As Fe content increases to $1.0 \mathrm{wt} \%$, the yield strength increases by $122 \mathrm{MPa}$ and the ultimate tensile strength increases by 113 $\mathrm{MPa}$, while the ductility decreases (Table 2). The fracture is termed ductile or brittle depending on the elongation (larger or small) and fractured surface (rough or smoother). From Figure 7, we can see the ductile-brittle transition clearly. The dimples in the fractured surface become deeper when Fe content increases to $0.5 \mathrm{wt} . \%$. While the fractured surface of ZTAFV alloys become smooth with further increasing of Fe content. Smooth fracture means that the alloy is brittle, which can be proved by the elongation of the alloy (Figure 6b). The ductile-brittle transition could be caused by the increasing of $\beta$ grain size and decreasing of $\alpha^{\prime}$ phase content, which could be observed from Figure 1 and Figure 4(b) and (c), respectively. The ductile-brittle transition may be also attributed to the dislocation density of the crack tip and increase of $\beta$ grain size [16]. As the atomic radius of Fe is smaller than those of Ti and 
$\mathrm{Zr}$, Fe addition could result in lattice distortion. The dislocation density increases with the increasing of Fe content. With Fe content increasing to $1.5 \mathrm{wt} \%$, ZTAFV-1.5 alloy has an ultimate tensile strength of $\sigma_{b} \approx 1667 \mathrm{MPa}$, but it exhibits a lower total elongation of $\varepsilon_{\mathrm{f}} \approx 2.34 \%$. The pinning effect of $\alpha^{\prime}$ lath plays a key role in the improvement of tensile strength, and the pinning effect and grain refinement work together for the ultra-high tensile strength of ZTAFV-1.5 alloy. XRD patterns show that no $\alpha^{\prime}$ phase exists in the ZTAFV-2 and ZTAFV-2.5 alloys. Thus the decrease of tensile strength is attributed to no pinning effect in the higher Fe content of ZTAFV-2 and ZTAFV-2.5 alloys. Deformation mode of ZTAFV alloys also changes with the different addition of Fe content. ZTAFV-2 and ZTAFV-2.5 alloys should be only slip in $\beta$ phase (bcc) [17]. While ZTAV, ZTAFV-0.5, ZTAFV-1, and ZTAFV-1.5 alloys are all composed of $\alpha^{\prime}+\beta$ phase, deformation mode of them should be slip in $\alpha^{\prime}$ phase (hcp). Therefore, the increasing of $\beta$ grain also plays an important role for the decreasing of tensile strength.

The strength enhancement could be also caused by solid solution strengthening. Fleischer demonstrated that the relationship of strength of metallic materials and the concentration of solute atoms can be expressed as $\sigma \propto \mathrm{c}^{2 / 3}$, where $\sigma$ is the strength and $\mathrm{c}$ is the concentration of the solute atom [18]. According to this relationship, the values of $\sigma$ can be estimated. Figure 8 replies the results of $\sigma$ as a function of the concentration of the solute atom Fe. It can be seen that the strength of the alloys increases with Fe contents from $0 \mathrm{wt} \%$ to $1.5 \mathrm{wt} \%$, while above $1.5 \mathrm{wt} . \%$, the strength decreases. The calculated results are in good agreement with the measured tensile 
strength.

\section{Conclusions}

In summary, the microstructure, phase transformation, mechanical properties of Ti-30Zr-5Al-3V- $x \mathrm{Fe}(x=0,0.5,1.0,1.5,2.0,2.5)(\mathrm{wt} \%)$ alloy have been investigated. The results show that the phase composition changes as $\alpha^{\prime}+\beta \rightarrow \beta$, grain size becomes small and lattice distortion is enlarged as Fe content increases. Ti-30Zr-5Al-3V-0.5Fe

exhibits a better mechanical property $\left(\sigma_{\mathrm{b}} \approx 1420 \mathrm{MPa}, \varepsilon_{\mathrm{f}} \approx 5.34 \%\right)$ than those of Ti-30Zr-5Al-3V $\quad\left(\sigma_{b} \approx 1302 \quad \mathrm{MPa}, \quad \varepsilon_{\mathrm{f}} \approx 4.28 \%\right)$. Highest ultimate tensile strength $\left(\sigma_{\mathrm{b}} \approx 1667 \mathrm{MPa}, \varepsilon_{\mathrm{f}} \approx 2.34 \%\right)$ have been achieved in Ti-30Zr-5Al-3V-1.5Fe. The grain refinement, phase composition, and solid solution strengthening could be contributed to the enhancement of mechanical properties of examined alloys.

\section{Acknowledgment}

This research is funded by NSFC (grant 51571174) and National Science Foundation for Distinguished Young Scholars for Hebei Province of China (grant E2016203376). J.Q would like to acknowledge the support from Thai Government Budget (2016), Chulalongkorn University (GRB_BSS_105_59_62_03), and State Key Laboratory of Metastable Materials Science and Technology, Yanshan University.

\section{References}

[1] D. Eylon, A. Vassel, Y. Combres, R.R. Boyer, P.J. Bania, R.W. Schutz, JOM, 46 (1994) 14-15.

[2] O.M. Ivasishin, P.E. Markovsky, Y.V. Matviychuk, S.L. Semiatin, Metallurgical and Materials Transactions A, 34 (2003) 147-158. 
[3] X.J. Jiang, X.Y. Wang, Z.H. Feng, C.Q. Xia, C.L. Tan, S.X. Liang, X.Y. Zhang, M.Z. Ma, R.P. Liu, Materials Science and Engineering: A, 635 (2015) 36-42.

[4] X.J. Jiang, Y.K. Zhou, Z.H. Feng, C.Q. Xia, C.L. Tan, S.X. Liang, X.Y. Zhang, M.Z. Ma, R.P. Liu, Materials Science and Engineering: A, 639 (2015) 407-411.

[5] X.J. Jiang, Y.K. Zhou, C.L. Tan, M.Z. Ma, R.P. Liu, Materials \& Design, 64 (2014) 21-24.

[6] S.X. Liang, L.X. Yin, R.J. Jiang, X.Y. Zhang, M.Z. Ma, R.P. Liu, Journal Of Alloys And Compounds, 603 (2014) 42-47.

[7] S. Liang, L. Yin, R. Jing, X. Zhang, M. Ma, R. Liu, Journal of Materials Research, 28 (2013) 2715-2719.

[8] S.X. Liang, L.X. Yin, R. Jing, X.Y. Zhang, M.Z. Ma, R.P. Liu, Materials \& Design, 58 (2014) 368-373.

[9] M.F. Ijaz, H.Y. Kim, H. Hosoda, S. Miyazaki, Materials Science and Engineering: C, 48 (2015) 11-20.

[10] J. Ning, X. Zhang, J. Qin, Y. Liu, M. Ma, R. Liu, Journal Of Alloys And Compounds, 618 (2015) 73-77.

[11] L. López Pavón, H.Y. Kim, H. Hosoda, S. Miyazaki, Scripta Materialia, 95 (2015) $46-49$.

[12] P. Xue, Y. Li, K. Li, D. Zhang, C. Zhou, Materials Science and Engineering: C, 50 (2015) 179-186.

[13] J. Du, J. Yang, M. Kuwabara, W. Li, J. Peng, MATERIALS TRANSACTIONS, 48 (2007) 2903-2908. 
[14] M.W. Z Liu, Y Weng, T Song, Y Huo, J Xie, Materials Transactions, 44(10) (2003;) 62.

[15] Y. Zhang, N. Ma, IOP Conference Series: Materials Science and Engineering, 117 (2016) 012005.

[16] G. Le Roy, J.D. Embury, G. Edwards, M.F. Ashby, Acta Metallurgica, 29 (1981) 1509-1522.

[17] S. Hanada, T. Yoshio, O. Izumi, Journal of Materials Science, 21 (1986) 866-870.

[18] R.L. Fleischer, Acta Metallurgica, 11 (1963) 203-209. 
Fig. 1. The XRD patterns of the Ti-30Zr-5Al-3V- $x \mathrm{Fe}(x=0,0.5,1.0,1.5,2.0,2.5)$.

Fig. 2. DSC curves of Ti-30Zr-5Al-3V- $x \mathrm{Fe}(x=0,0.5,1.0,1.5,2.0,2.5)$.

Fig. 3. TEM images and corresponding SAED patterns of ZTAV (a), and ZTAFV alloys with Fe content of 0.5 wt.\% (b), 1 wt.\% (c), and 1.5 wt.\% (d).

Fig. 4. Optical micrographs of ZTAV (a), and ZTAFV alloys with Fe content of 0.5 wt.\% (b), 1 wt.\% (c), 1.5 wt.\% (d), 2.0 wt.\% (e), 2.5 wt.\% (f).

Fig. 5. Stress-strain curves of ZTAV (a), and ZTAFV alloys with Fe content of 0.5 wt.\% (b), 1 wt.\% (c), and 1.5 wt.\% (d), 2 wt.\% (e), and 2.5 wt.\% (f).

Fig. 6. Relationship between tensile strength and Fe content (a) and relationship between elongation and $\mathrm{Fe}$ content (b) and the microhardness of alloy Ti-30Zr-5Al-3V- $x \mathrm{Fe}(x=0,0.5,1.0,1.5,2.0,2.5)(\mathrm{c})$.

Fig. 7. Fractographs of ZTAV(a) and ZTAFV alloys with Fe content of 0.5 wt.\%(b) to 2.5 wt. $\%(f)$.

Fig. $8 \sigma$ value as a function of the concentration of the solute atom Fe. 


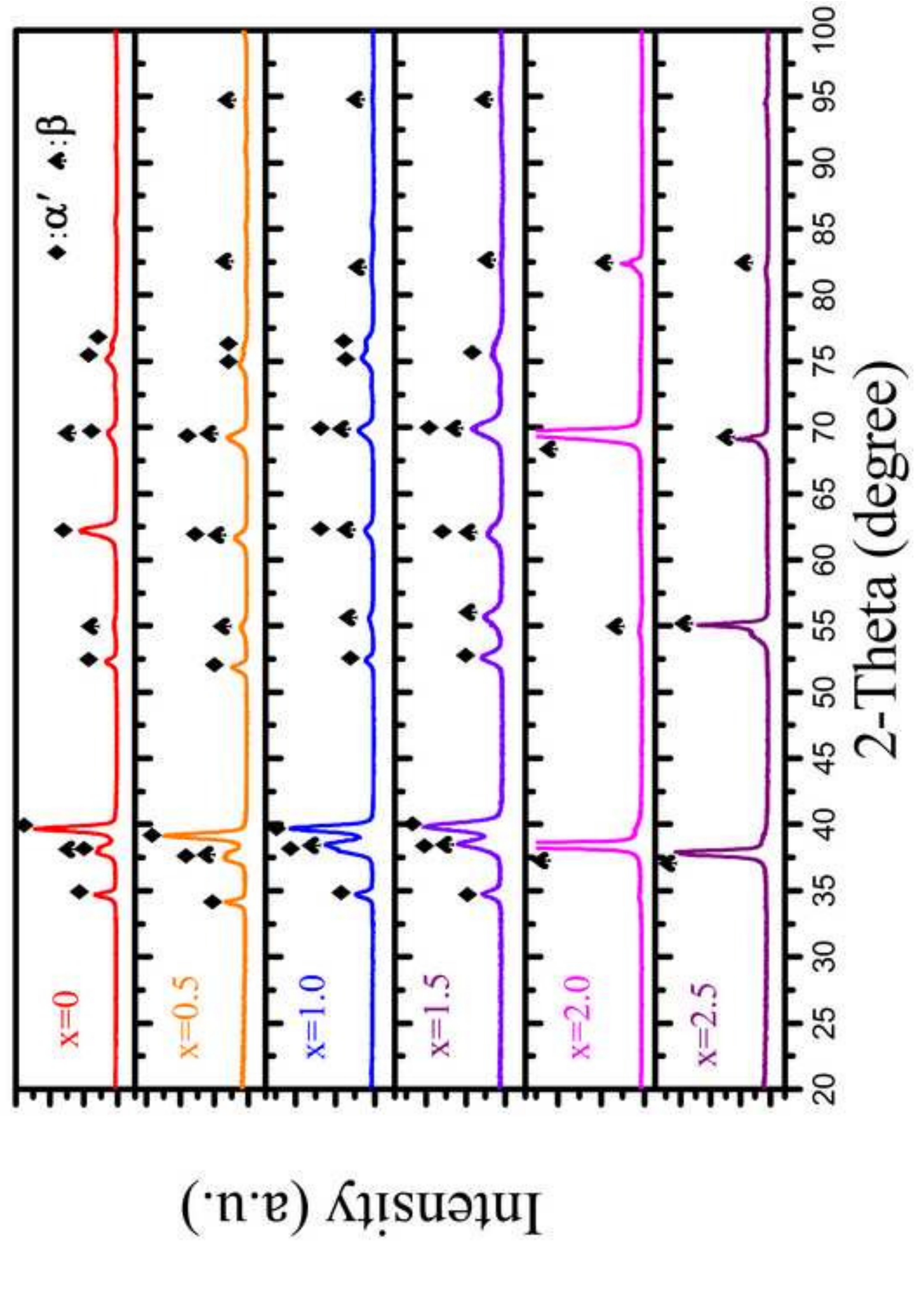




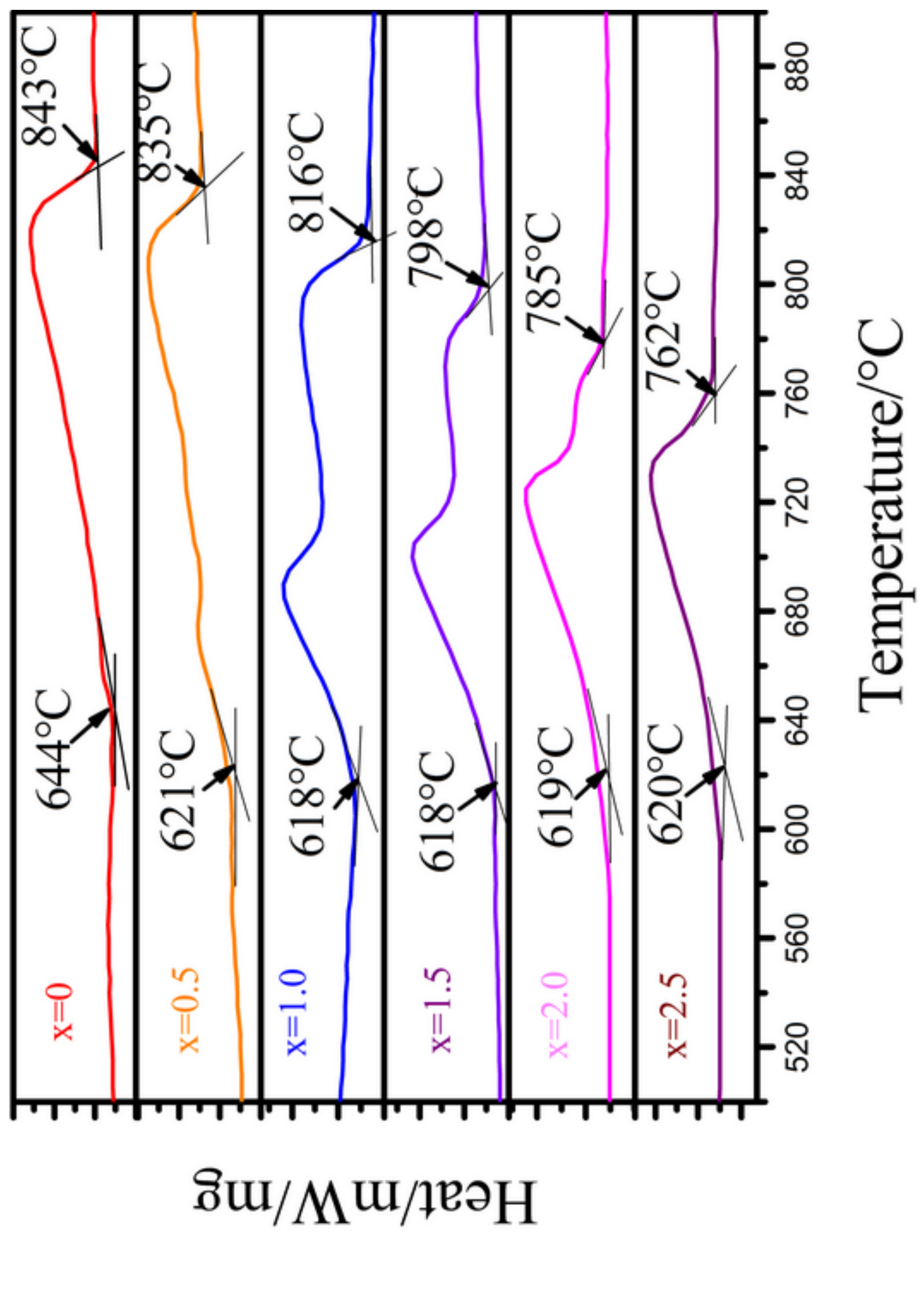



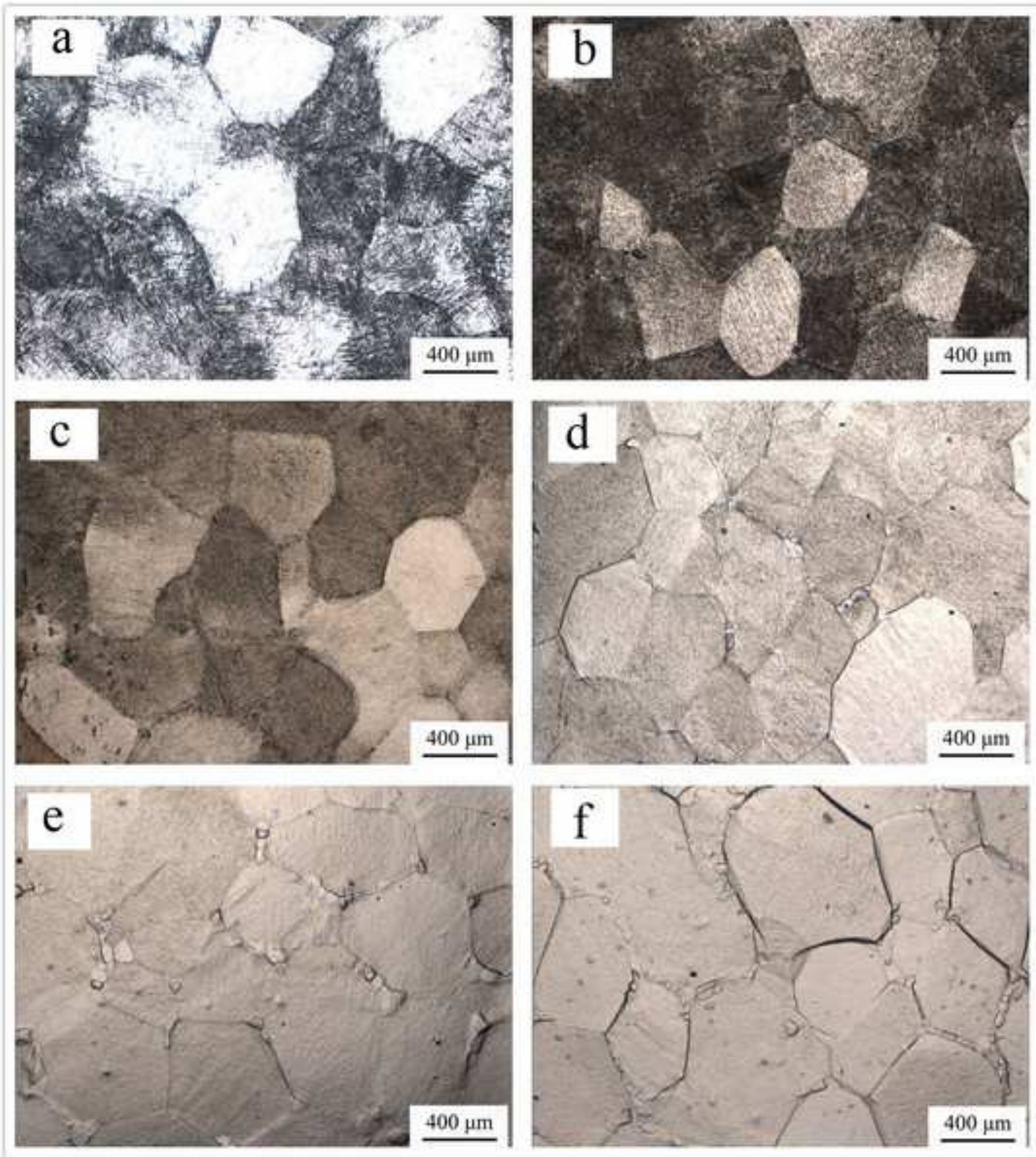

Figure 3 

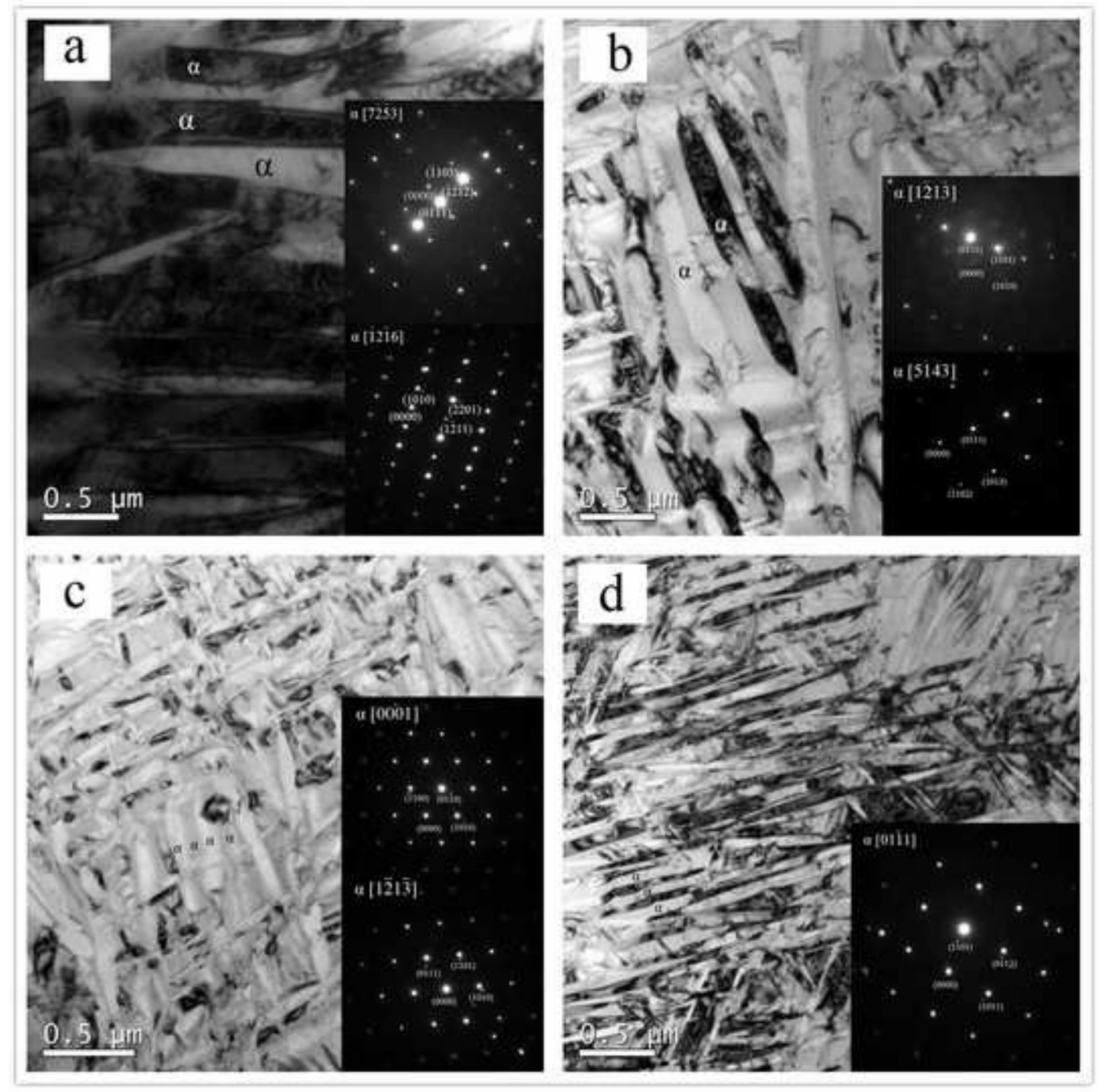

Figure 4

4

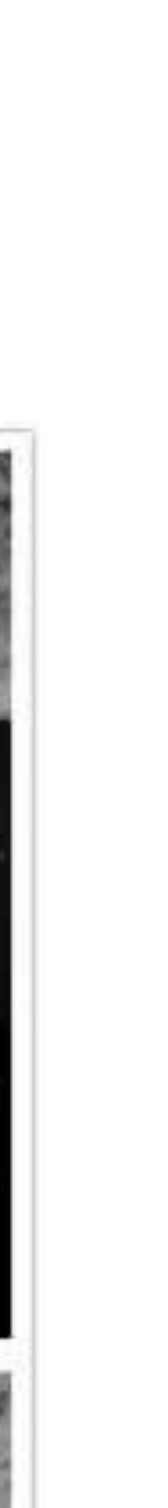

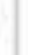

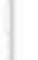

.




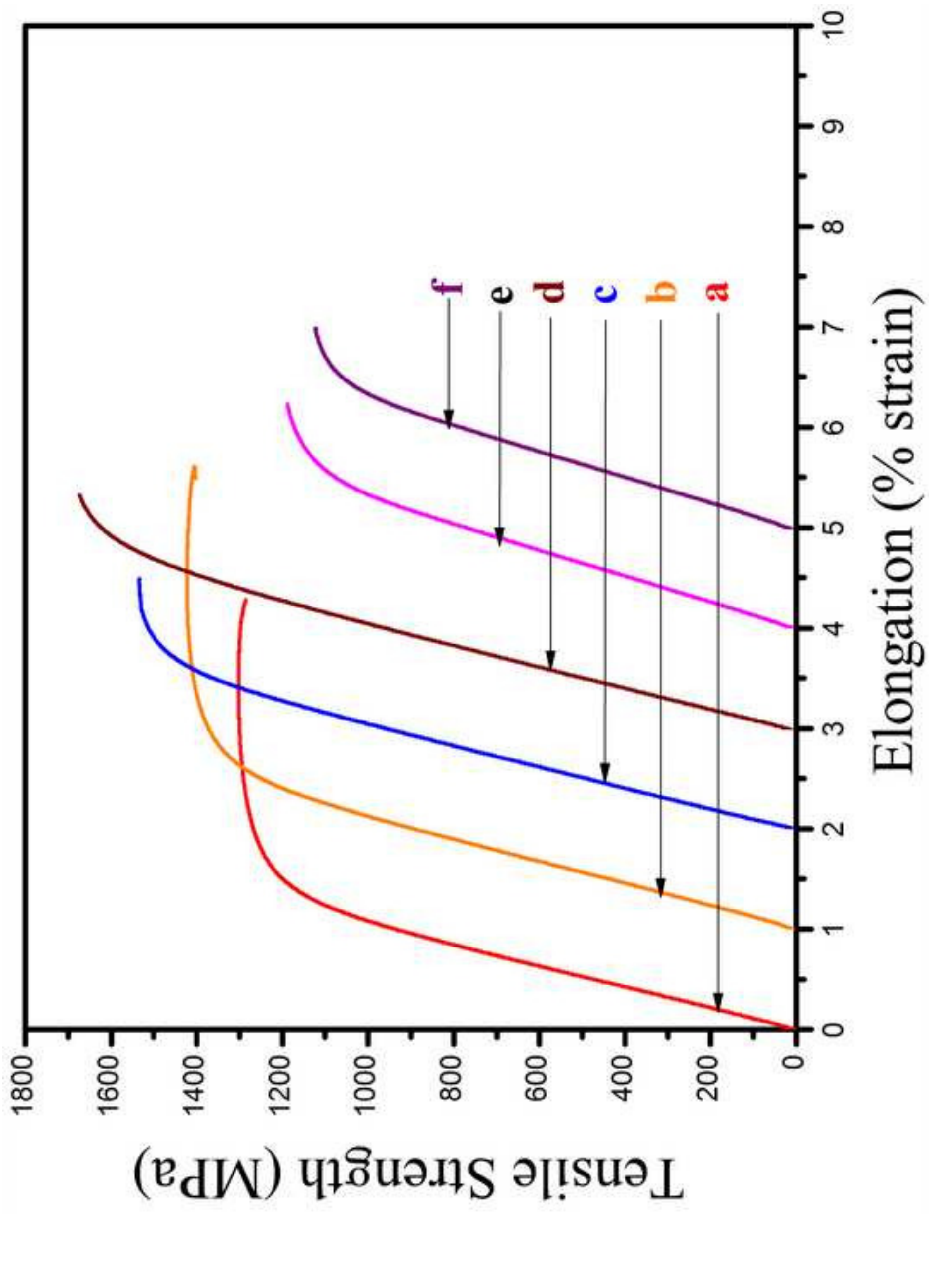




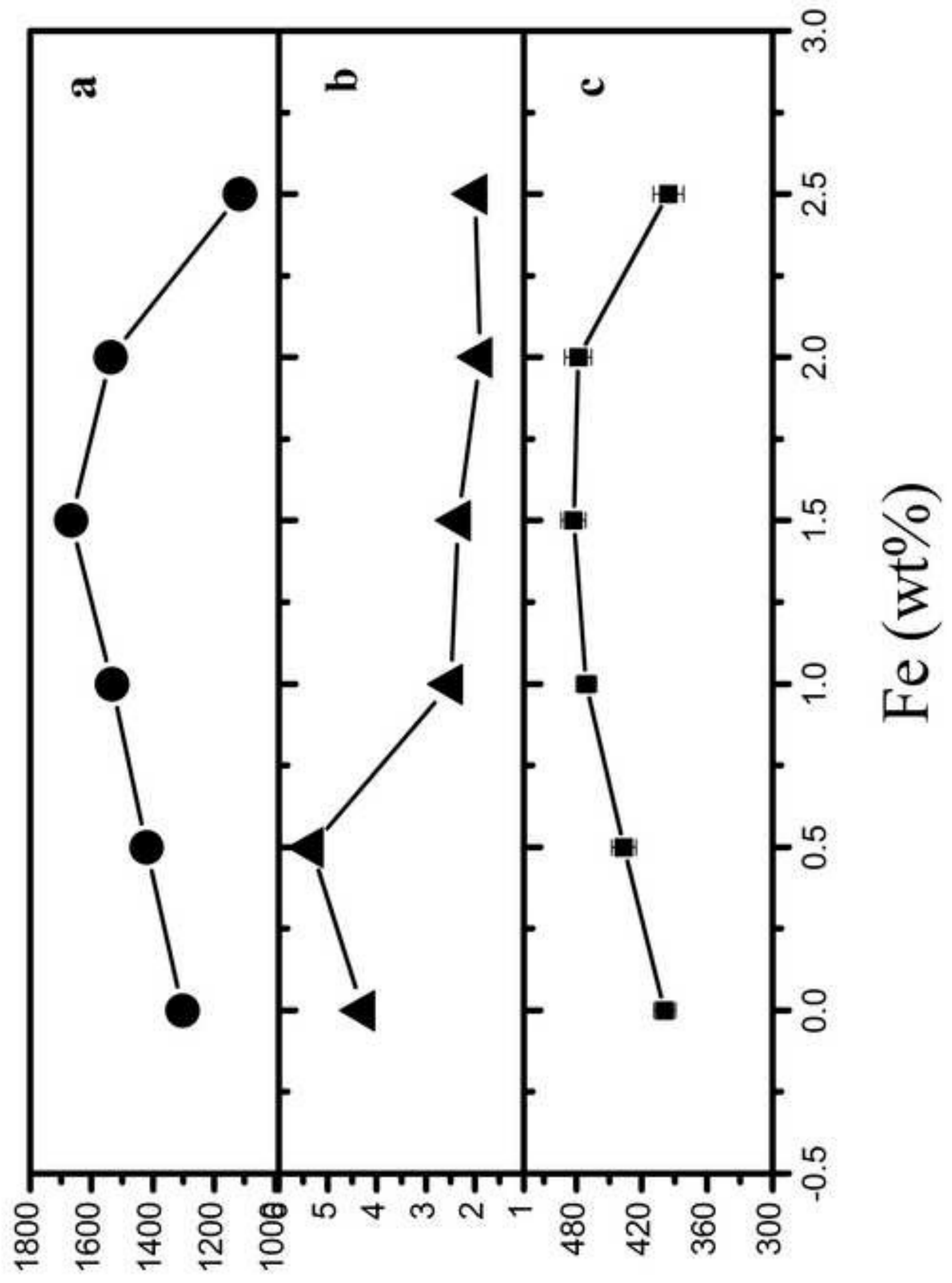

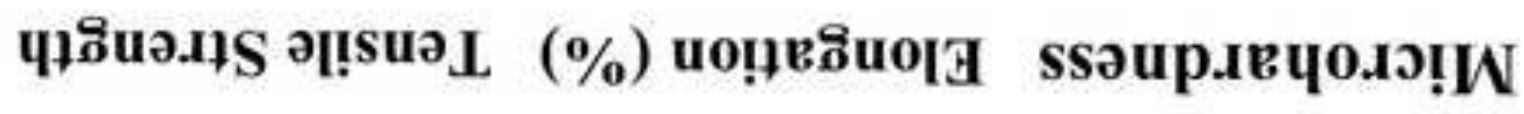



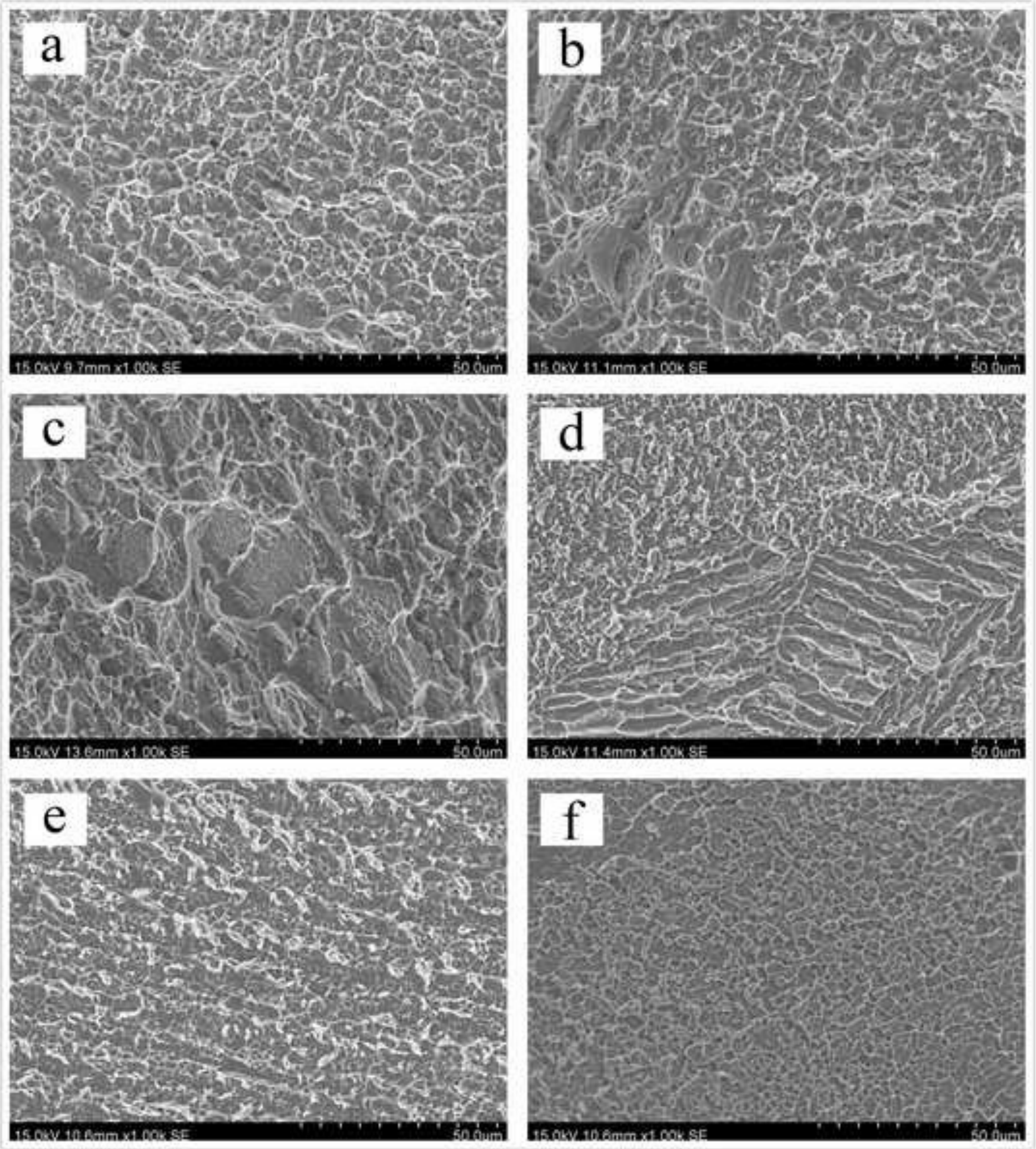


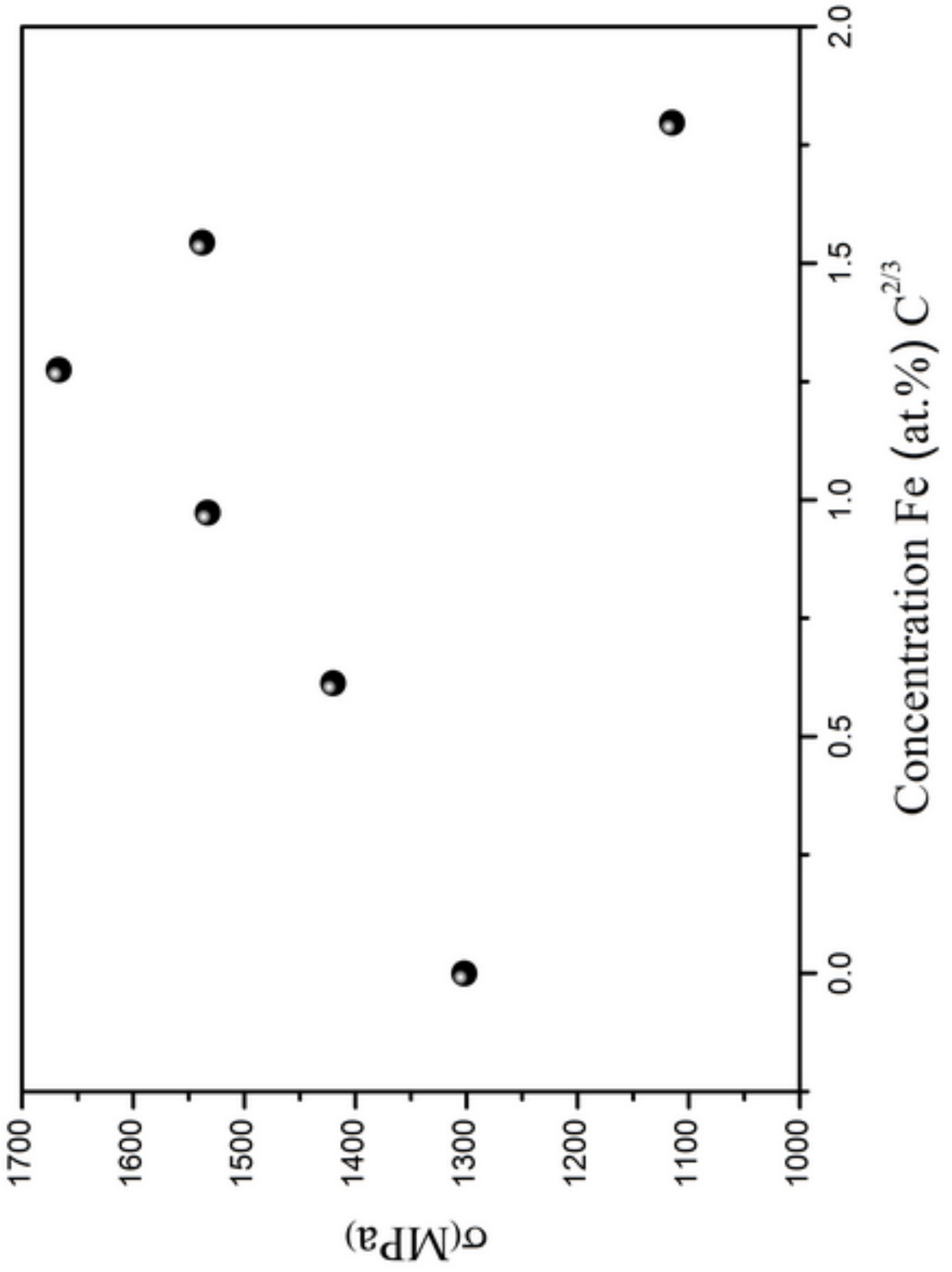

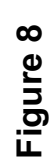

